\title{
PERSPECTIVES REGARDING THE IMPACT OF CLIMATE CHANGE ON WORLD ECONOMY
}

\author{
Bianca Georgiana OLARU, Cristian Silviu BĂNACU \\ The Bucharest University of Economic Studies, 6 Piata Romana, $1^{\text {st }}$ District, Bucharest, 010374, Romania \\ e-mail: biancageorgiana.olaru@gmail.com
}

\begin{abstract}
By elaborating this article, we want to analyse the current situation, but also anticipating the actions that will result from climate change and its impact on global economy. Firstly, it is necessary to clarify the terms of specialty, a brief introduction to climate change, but also the presentation of legislative concepts at national, European and international level. Secondly, we shall briefly outline some possible scenarios on global climate change, but also various strategies and policies that can help achieve the expected climate change outcomes. Further, present and future situations will be presented by geographic regions, but also differentiated according to the large economic production flows, and finally, the main effects of climate change on the world economy will be identified.
\end{abstract}

KEYWORDS: climate change; global economy; legislative concepts; production flows

\section{Introduction}

Nowadays, large-scale discussions are being held about climate change because they have several repercussions on environment, economy, agriculture, and other sectors of activity. Agriculture is one of the main sectors directly affected by climate change, leading to a reduction in agricultural output, and implicitly, reducing the economy of the country affected by extreme weather phenomena. Adaptation to climate change is the way to reduce/eliminate the negative effect of climate change on agricultural produce, but also implicitly, on the economy' [1].

According to the IPCC (2013), the increase in greenhouse gas emissions has contributed to the emergence of climate change caused by man, emissions from the past already determining its size by mid-century and current and future emissions ' (i.e. global emissions cuts) which determines the severity of climate change. Also, according to IPCC 2014, adapting to climate change at regional or local level is a field of political involvement, which is of importance for maintaining in good conditions the ecological environments, economic and social situation of a country. The overall objective of this article is to raise awareness of the importance of climate change, as well as highlighting their impact on the global economy [2].
The specific objectives relate to the following aspects, namely: (i) understanding of climate change legislation, (ii) reducing disruptive actions that can lead to accelerating climate change; (iii) presenting present and future scenarios for each study area; (iv) highlighting the impact on geographic regions and production flows. According to the United Nations Framework Convention on Climate Change (UNFCCC) by the adoption of the Paris Climate Change Agreement, the stakeholders consider it necessary to support the implementation of long-term objectives through coordinated and effective action for good sustainable development and the eradication of poverty at national level. So, this agreement seeks to: promote mitigation and adaptation measures; improve the participation of the public and private sector in the implementation of appropriate national solutions; create opportunities for co-ordination between user tools and institutional arrangements [3].

\section{Approaches and contributions general on climate change}

Factors that influence the current state of the climate act differently across the globe, and for this reason effects and impacts are otherwise different depending on the geographical region. In this respect, it can be seen from previous studies that climate 
change is happening at a faster pace in the vicinity of the poles compared to other regions around the globe.

The most important natural factors are represented by:

(a) distance from the sea;

(b) ocean currents;

(c) wind direction;

(d) the form of the land;

(e) the distance from the equator;

(f) the phenomenon El Niño.

This phenomenon (El Niño) contributes to the modification of wind and precipitation patterns, it can lead to the occurrence of droughts and floods, especially in the areas adjacent to the Pacific. For example, due to this phenomenon, tornadoes occurred in Florida, smog in Indonesia and forest fires in Brazil. In addition to the natural factors, we must also consider the anthropic ones, because man can influence the climate through his actions. People influence the climate and temperatures by burning fossil fuels, cutting forests, raising livestock and intensifying agriculture. Natural and anthropogenic factors contribute to increasing gas emissions, increasing the greenhouse effect and the global warming phenomenon.

\section{National, European and international legislation}

At global level, there are the following agreements between the partner states:

- United Nations Framework Convention on Climate Change (UNFCCC). This Convention was established in 1992 with the role of decision-making forum for international action on climate change, and 195 countries have joined this international agreement. Its main purpose is to achieve ... maintains greenhouse gas concentrations in the atmosphere at a level that prevents dangerous anthropogenic interference with the climate system. Such a level should be achieved within a period enough to allow ecosystems to adapt naturally to climate change, to ensure the necessary food production and to enable sustainable economic development' [3].

- The Kyoto Protocol

Under the Kyoto Protocol adopted at international level, 37 industrialized countries in the period 2008-2012 to fulfil the criteria for reducing greenhouse gas emissions by an average of $5 \%$ over the 1990 limits. Also, the UK has committed to reducing its greenhouse gas emissions by $12.5 \%$. The proposed objective was achieved, and the 37 countries have managed to reduce their greenhouse gas emissions by more than $10 \%$. But there are still countries where greenhouse gas emissions have increased over the period 2008-2012, for example China. This Kyoto Protocol was also agreed for the period 2013-2020, but the signatory countries ratified in a smaller number than the original ones [3].

The Paris Agreement

The UNFCCC has continued negotiations with the states concerned and the result was the adoption of the Paris Agreement in 2015. Significant global effort to reduce greenhouse gas emissions was signed in order to sign this agreement [3].

Thus, 160 UNFCCC stakeholders have committed themselves to reducing their greenhouse gas emissions by 2030, including China, the US and the European Union. The main objective of the Paris Agreement is to avoid raising the global average temperature by more than $2{ }^{\circ} \mathrm{C}$ above pre-industrial levels and continuing efforts to limit global warming to $1.5^{\circ} \mathrm{C}$. The Paris Agreement provides for a review of commitments in 2018 and another review will take place in 2023 and further revisions every five years after this last deadline. In terms of European legislation in the field of climate change, this is represented by the following acts:

- Decision 2016/590 / EU concerning the execution, on behalf of the European Union, of the Paris Agreement adopted under the United Nations Framework Convention on Climate Change;

- Directive 2014/52 / EU amending Directive 2011 / EU refers to the need to assess the impact of climate and climate change vulnerability projects. In this respect, it is considered that the measurement of impacts and risks related to climate change and research into methods of reducing vulnerability is of importance;

- Directive 2003/87/EC of 13 October 2003 (Directive 2003/87) establishes a scheme for GHG emission allowance trading (the Emissions Trading Scheme, ETS) within the Community and amending Council Directive 96/61 establishing the EU scheme for GHGs. The Directive entered into force on 25 October 2003;

- Other implementing provisions refer to Commission Regulation (EC) No. 916/2007 of 31 July 2007 amending Regulation (EC) No. 2216/2004 for a standardised and secured system of registries pursuant to Directive 2003/87/EC of the European Parliament and of the Council and Decision No. 280/2004/EC of the European Parliament and of the Council; and Commission Decision 2007/589/EC of 18 July 2007 establishing guidelines for the monitoring and reporting of GHG emissions (COM (2007) 3416);

- Decision No. 280/2004 of 11 February 2004 concerns a mechanism for monitoring Community GHG emissions and for implementing the Kyoto Protocol. This Decision establishes a new mechanism for monitoring and reporting GHG emissions to 
ensure more accurate evaluation and more regular monitoring of the progress made in reducing emissions;

- Decision No. 2005/166 of 10 February 2005 (Decision No. 2005/166) lays down rules implementing Decision No. 280/2004 concerning a mechanism for monitoring Community GHG emissions and for implementing the Kyoto Protocol, as described above, and establishes rules implementing Decision No. 280/2004 as regards to the reporting of information referred to in articles 3(1) and (2) of Decision No. 280/2004, in accordance with article 3 (3) of that Decision;

- Decision No. 2006/944 of 14 December 2006 (Decision No. 2006/944) determines the respective emission levels allocated to the Community and each of its member states under the Kyoto Protocol pursuant to Decision No. 2002/358. The Annex to Decision No. 2006/944 sets out the emission levels in terms of tonnes of $\mathrm{CO}_{2}$ equivalent allocated to the Community and to member states for the first quantified emission limitation and reduction commitment period under the Kyoto Protocol;

- Decision No. 406/2009 on effort sharing, which came into force on 25 June 2009, sets different (i.e. burden sharing) targets for each member state and provides binding GHG emissions limits for certain categories of emissions that are not subject to the EU ETS for the period 2013 to 2020, to contribute to the EU's overall 20 per cent cutting GHG emissions objective. Through this measure, stricter GHG emissions cuts may be implemented if an international climate change agreement is reached to succeed the Kyoto Protocol;

- The European Commission has adopted new Environmental and Energy Aid Guidelines, which will be valid from 1 July 2014 until the end of 2020 . Notably, it includes new provisions on aid to energy infrastructure to facilitate investment into Smart Grids to promote energy efficiency and cross-border interconnection as it helps to strengthen the internal energy market as well as providing support for system stability and generation adequacy [3].

Regarding the national legislation, Romania respects the international and European legislative provisions, but also on the existing national ones, such as:

- Decision no. 1026/2014 for the reorganization of the National Commission on Climate Change. The National Commission on Climate Change is an interministerial body with consultative role, without legal personality, whose activity is coordinated by the central public authority for environmental protection and climate change;

- Decision to approve the National Strategy on Climate Change and Growth based on low carbon emissions for the period 2016-2020 and the National
Action Plan for the implementation of the National Strategy on Climate Change and Growth based on low carbon emissions for the period 2016-2020 [4].

\section{Possible scenarios on the evolution of global climate change}

Climate change does not act the same in all places of the world, causes and consequences are different, and poor economies are more vulnerable to the threat of climate change impacts. In general, climate projections for the next 100 years are wide in scale due to differences in model response and scenario response time, and the difference is given by the model chosen to identify these scenarios. According to the Intergovernmental Panel on Climate Change (IPCC) an increase in global greenhouse gas emissions is expected, indicating an increase in global average temperatures of at least $3{ }^{\circ} \mathrm{C}$ to 2100 compared to $1850-1900$ [3].

\section{Emissions go from bad to worse}

The new report from the Global Carbon Project shows global emissions are following the course of the worst of four scenarios* This suggests warming of at least $3^{\circ} \mathrm{C}$ by 2100 , relative to $1850-1900$

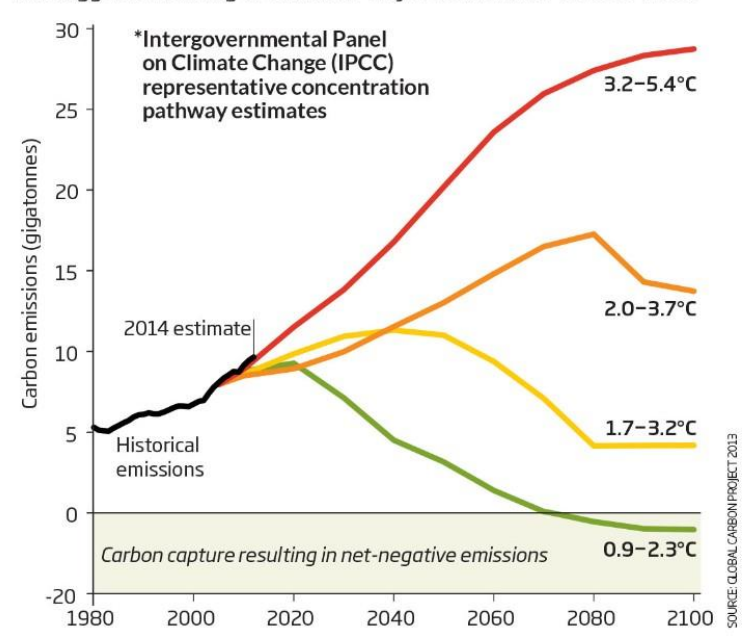

Fig. 1. Global emissions scenarios [5]

\subsection{Main trends and possible effects}

Globally, climate change can have visible effects on the environment, namely through the following actions: melting glaciers, the breakage of ice from rivers and lakes earlier than normal, changing the cycle of plants and animals to adapt to these conditions, the flowering of trees that can occur earlier than usual. In the past, researchers in the field predicted changes that could result from climate change: reducing the amount of ice from the sea, accelerated sea level rise, and heat waves that manifest with a higher intensity. So, the 
Intergovernmental Panel on Climate Change (IPCC) indicates that the hypotheses published so far confirm that the net cost of climate change destruction is significant and may increase over time, which could lead to a global economic downturn. Those skilled in the art argue that global average temperatures may increase by up to 1.8 to 5.4 degrees Fahrenheit (approximately $1 \ldots 3{ }^{\circ} \mathrm{C}$ ) than those recorded in the 1990 period. Regarding the emergence of the effects of climate change, some NASA specialists state that these are due to the human factor, namely the greenhouse effect that leads to global warming. The greenhouse effect is produced by gases that contribute directly, such as water vapor, carbon dioxide, methane, nitrogen oxide, chlorofluorocarbons (CFCs). The main possible effects that may be due to climate change are:

- sea level rise and ocean acidification, which occur due to increased water molecules when temperatures are higher, significant precipitation and melting glaciers. Increased temperatures lead to the disappearance of coral reefs in the oceans, but also to the occurrence of extreme weather events;

- changes due to rising temperatures will result in higher drought phenomena in some areas of the world, and others will have higher rainfall than usual. Extreme weather events refer to the appearance of very hot summer weather, colder winters than normal, strong storms with electric discharge, but also hurricanes in some geographic areas. Globally, climate models estimate that global warming will cause significant changes in climate models in terms of wind intensity, rainfall and temperature variations;

- melting glaciers, a phenomenon that has long been discussed by researchers in the field. In this regard, it is estimated that the melting of polar ice in the Arctic and Antarctic regions, along with the melting of the glaciers and glaciers in Greenland, North America, South America, Europe and Asia, can lead to the rise of the sea;

- changing fauna and flora as birds migrate from equator to poles due to global warming;

- human communities will be affected by these effects that contribute to the drought phenomenon in certain agricultural areas, snow drop in winter, extreme weather events, changing seasons of vegetation, all of which can produce reduced crop yields and increase fewer animals [2].

Legislative and executive acts up to 2016

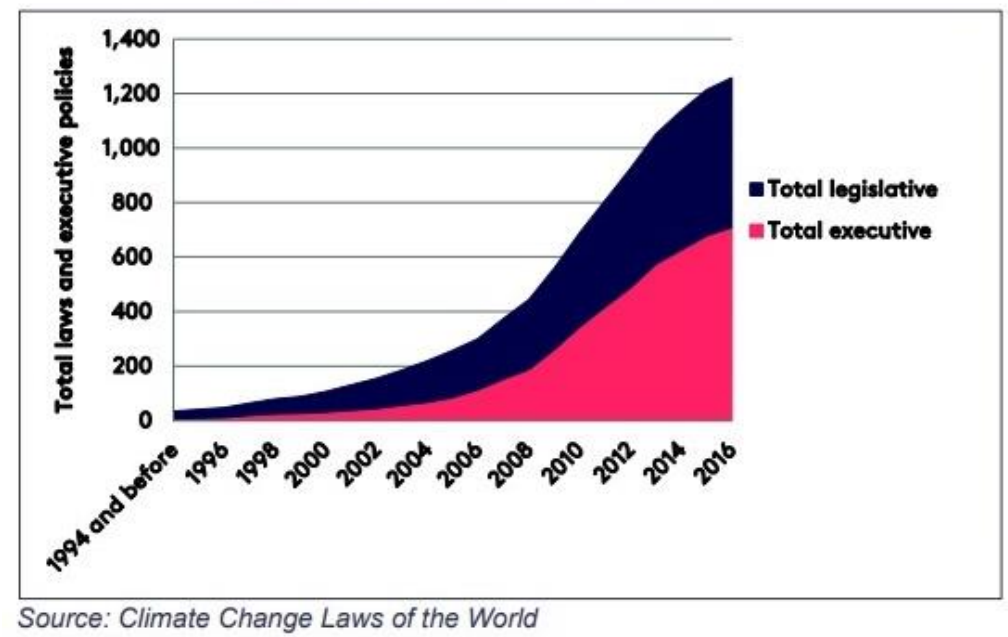

Fig. 2. Legislative and executive acts up to 2016 [4]

Following the adoption of the Kyoto Protocol, the number of legislative norms on climate change has substantially changed, so at the end of 2016 there were over 1200 laws and policies in the 164 participating states (Figure 2, according to the Global Trends in Climate Change and Law Litigation).

Worldwide, but also Europeans tackle differently climate change, that is why research is done through solutions and legislation implemented in other countries to better manage extreme weather phenomena. Some states rely only on legislative and others focus on the implementation of climate change strategies and plans.

According to the figures above (Figure 3), there is a worldwide increase in the number of law spreads in 2017 compared to 1997 , which refers to the importance and awareness of legislative measures on adaptation to climate change, even though the poorest countries in the world do not have the right tools (Guinea, Libya, Somalia, Sudan, etc.). 

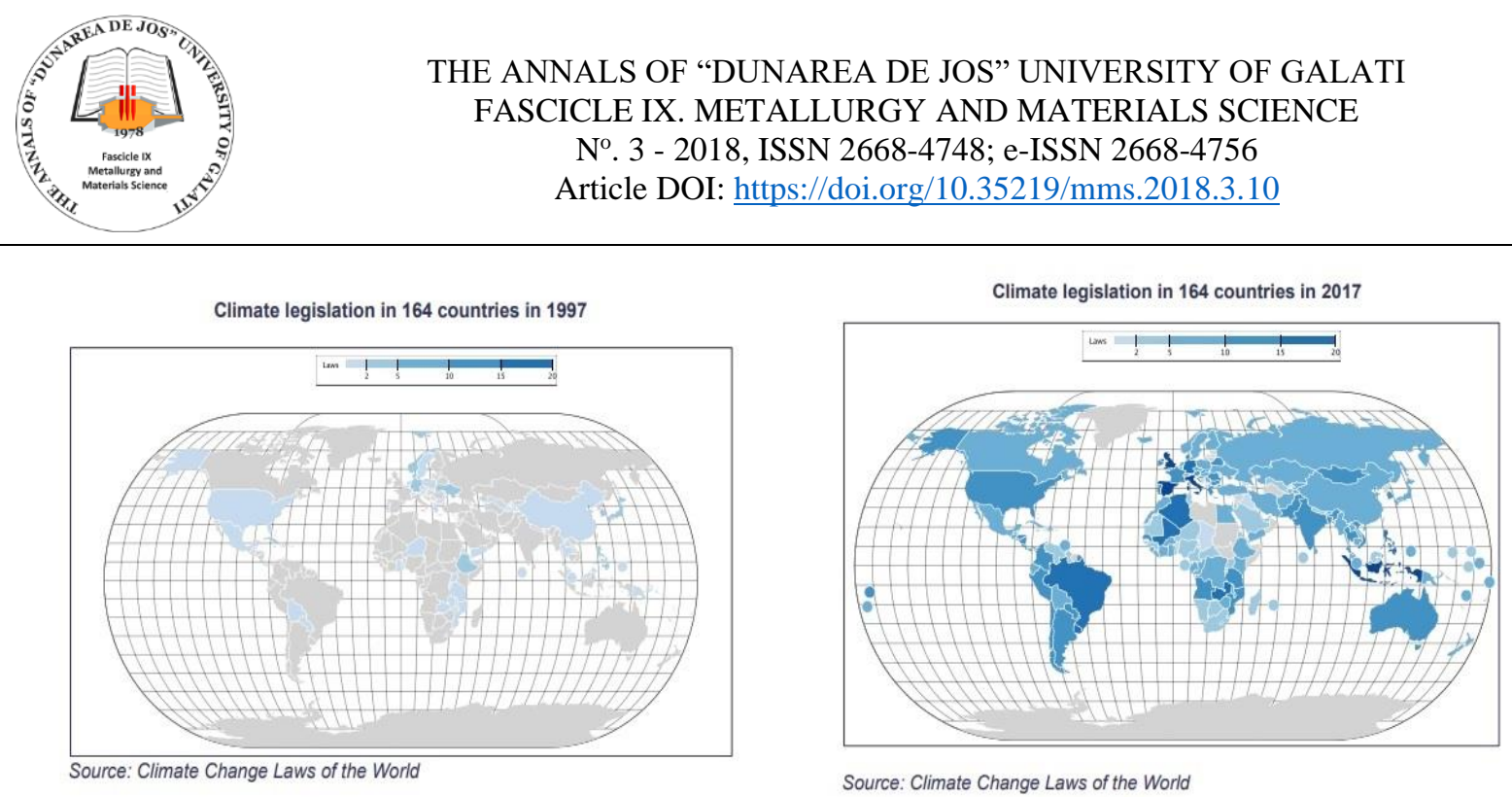

Fig. 3. Climate legislation-comparison between 1997 and 2017 [4]

\subsection{Global economy in the context of climate change}

According to studies conducted so far, in order to reduce carbon emissions that can lead to the global warming effect, it is necessary to identify ecological and economic solutions that minimize the use of fossil fuels.

Economic experts have analysed cost estimates for achieving the Paris agreement's goal of reducing carbon emissions and maintaining global average temperatures not exceeding $2^{\circ}$ and they stated that limiting global actions would require about $1.5 \%$ of total income. At the same time, other researchers say the cost could exceed $4 \%$ of global income.

Cost-benefit analysis is a commonly used method that provides return on investment in climate change and the results obtained may lead to legislative, but also political support for taking the necessary measures. However, besides the costbenefit ratio, we must consider the implications of the efficiency and effectiveness of the measures needed to prevent the effects of climate change. In this case, the approaches identified must take account market requirements and propose that the main private sector producers should modify their techniques and current environmental behaviour by using innovative, environmentally friendly and economic tools / technologies. However, the governments and ministries involved have an important role to play in implementing tools and policies to manage present and future situations, taking into account the implications of the activities and processes of companies/companies that can generate carbon emissions into the atmosphere, and thus, to lead to environmental pollution. For example, the instruments that can contribute to reducing greenhouse gas emissions are the application of pollution taxes and transferable/tradable permits.

\subsection{The impact of climate change on the global economy}

In general, on the long term, it seems that the impact of climate change on the world economy will be a negative one. Global warming could lead to a downturn in the economy, as effects will affect countries' stability due to rising carbon dioxide emissions and global average temperatures. The sector of activity directly affected by climate change is agriculture, as the drought decreases the yield of crops leading to a decrease in food production, then to affect the income of the population. All these effects and many others contribute to higher electricity costs due to high consumption, rising inflation and the phenomenon of mass migration from areas prone to natural disasters (drought, floods) to non-risk areas.

\section{Conclusions}

In conclusion, global economy will suffer from climate change and this essay was aimed at informing and raising awareness of the public about the effects that can occur and can manifest differently in the world and that is why, it depends on the gravity/intensity/severity of the phenomenon taking into account the geographical area.

The economy can be disturbed by extreme weather events by reducing workforce and productivity, but also of gross capital. In this context, the inflation can increase due to low agricultural output that affects the cost of food and energy consumed for their production. Measures to reduce and mitigate climate change may restrict a state's budget, because they involve additional costs and that is why, it is intended to limit global warming and adaptation to climate change in the early stages so as not to need additional costs after extreme weather events/events. The subject is one that causes 


\section{THE ANNALS OF “DUNAREA DE JOS” UNIVERSITY OF GALATI \\ FASCICLE IX. METALLURGY AND MATERIALS SCIENCE \\ No. 3 - 2018, ISSN 2668-4748; e-ISSN 2668-4756 \\ Article DOI: https://doi.org/10.35219/mms.2018.3.10}

widespread discussions, and companies/institutions, together with the governments and ministries involved, must work together to implement strategies/plans, measures and recommendations for adaptation to climate change. An important step is the 'Paris Agreement', which provides limitation of gas emissions in the atmosphere as they lead to global warming. However, a sustainable solution would be that private sector companies could be forced through policies adopted to meet the carbon dioxide removal thresholds and reduce pollution resulting from the activities undertaken. In order to achieve the primary objective of reducing carbon dioxide emissions on a global basis, all institutions involved should have legislative support with collective support.

\section{References}

[1]. Lobell D. B., Climate change adaptation in crop production: beware of illusions, Glob. Food Sec. 3, p. 72-76, 2014.

[2]. Pachauri R. K., Reisinger A., Contribution of Working Groups I, II and III to the Fourth Assessment Report of the Intergovernmental Panel on Climate Change (IPCC), IPCC, Geneva, Switzerland, p. 104.

[3]. ***, UNFCCC, Paris Agreement.

[4]. ***, Climate Change Laws of the World, Policy brief Global trends in climate change legislation and litigation.

[5]. ***, New Scientist, https://www.newscientist.com. 